\title{
PUMPING BEHAVIOR OF ION PUMP ELEMENTS AT HIGH AND MISALIGNED MAGNETIC FIELDS*
}

\author{
H.C. Hseuh, ${ }^{+}$W.S. Jiang and M. Mapes \\ AGS Department, Brookhaven National Laboratory \\ Associated Universities, Inc. \\ Upton, New York 11973-5000
}

\begin{abstract}
The pumping speeds of several diode type ion pump elements with cell radii of $5 \mathrm{~mm}$, $5.5 \mathrm{~mm}, 6 \mathrm{~mm}, 9 \mathrm{~mm}$ and $12 \mathrm{~mm}$ were measured while being subjected to a magnetic field $\mathrm{B}$, ranging from 500 Gauss up to $15 \mathrm{KG}$, and misalignment angles (angles between the direction of $B$ and the anode axis) from 0 to 13 degrees. The pumping speeds of elements with the $9 \mathrm{~mm}$ and $12 \mathrm{~mm}$ cells peaked around $1-2 \mathrm{KG}$, then dropped off rapidly with an increasing magnetic field. The pumping speeds of the smaller cell elements remained constant with an increasing magnetic field. The pumping speeds of all the elements decreased with increasing misalignment. The measured pumping speeds from this study are 3-4 times lower than the calculated pumping speeds using previously reported empirical formulae.
\end{abstract}

\section{INTRODUCTION}

For the precision measurement of the muon $\mathrm{g}-2$ value, a muon storage ring, ${ }^{1}$ called $\mathrm{g}-2$ hereafter, is being constructed at Brookhaven's Alternating Gradient Synchrotron (AGS). The principle equipment of the storage ring is a continuous superconducting magnet with a diameter of $14 \mathrm{~m}$, which bends and stores the injected pion and muon particles. A magnetic field of 14.5 KG with a field homogeneity of $1 \mathrm{ppm}^{1}$ is required in the muon storage region, which rules out

*Work performed under the auspices of the U.S. Department of Energy.

+email: IN\%"HSEUH@BNLDAG.AGS.BNL.GOV" 
the use of the conventional lumped ion pumps for the $\mathrm{g}-2$ beam vacuum. DIPs have been used extensively in the bending magnet chambers of the electron storage rings as the main high vacuum pumps. In the $\mathrm{g}-2$ beam chambers, twenty four locations of $5 \mathrm{~cm}$ by $50 \mathrm{~cm}$ are available for the installation of the DIPs. The magnetic field at these locations ranges from 12 to $15 \mathrm{KG}$ and the alignment angles $\theta$ (angle between the direction of $\mathrm{B}$ and the DIP anode axis) from $0^{\circ}$ to $9^{\circ}$. To optimize the design of the DIPs for $\mathrm{g}-2$, the pumping behaviors of the Penning cells of various dimensions in this high but non-homogeneous magnetic field were characterized.

The pumping speed of the Penning cell is a function of $B$, the arode voltage $V$ and-the geometry of the cells. To prevent high voltage breakdown, $\mathrm{V}$ is usually set around $5 \mathrm{kV}$. With the known $\mathrm{B}$ and $\mathrm{V}$, the pumping speed $\mathrm{S}$ can be maximized by optimizing the geometry of the pump elements. Empirical formulae have been used by accelerator scientists to derive the optimum dimensions of the elements, such as the cell radius $R$, the cell length $L$, and the gaps $\delta$ between the anodes and the cathode plates, and to estimate the achievable $S$. The details of these formulae can be found in References 2 and 3, and will only be described briefly.

Maleve $^{2}$ proposed the first practical formulae for deriving the geometry of the Penning cells. Based on his formulae, S increases with increasing B, R, L and V. Hartwig and Kouptsidis ${ }^{3}$ pointed out later that $S$ peaks at a transition magnetic field, $B_{t r}$, with

$$
\mathrm{B}_{\mathrm{tr}}=7.63 \cdot \mathrm{V}^{0.5} /\left(\mathrm{R} \cdot \mathrm{P}^{0.05}\right)
$$

They proposed different formulae for $S$ at magnetic field below $B_{t r}$ and above $B_{t r}$. For $B<B_{t r}$, $S$ is a function of $L, R, B$ and the pressure $P$. For $B \geq B_{t r}, S$ is almost independent of $R$ and $B$ and can be expressed as

$$
\mathrm{S} \approx 9 \times 10^{-4} \cdot \mathrm{L} \cdot \mathrm{V} \cdot \mathrm{P}^{0.1} \cdot\left\{1-1.5 \times 10^{4}\left[\left(\mathrm{~B}-\mathrm{B}_{\mathrm{tr}}\right) \mathrm{R} \cdot \mathrm{P}\right]^{0.5} / \mathrm{V}\right\}
$$




\section{DISCLAIMER}

This report was prepared as an account of work sponsored by an agency of the United States Government. Neither the United States Government nor any agency Thereof, nor any of their employees, makes any warranty, express or implied, or assumes any legal liability or responsibility for the accuracy, completeness, or usefulness of any information, apparatus, product, or process disclosed, or represents that its use would not infringe privately owned rights. Reference herein to any specific commercial product, process, or service by trade name, trademark, manufacturer, or otherwise does not necessarily constitute or imply its endorsement, recommendation, or favoring by the United States Government or any agency thereof. The views and opinions of authors expressed herein do not necessarily state or reflect those of the United States Government or any agency thereof. 


\section{DISCLAIMER}

Portions of this document may be illegible in electronic image products. Images are produced from the best available original document. 


\section{DISCLAIMER}

Portions of this document may be illegible in electronic image products. Images are produced from the best available original document. 

However, several recent studies ${ }^{4-6}$ indicated that $\mathrm{S}$ increased with $\mathrm{R}$ even at high $\mathrm{B}$. To explain the dependence of $\mathrm{S}$ on $\mathrm{R}$ at high $\mathrm{B}$, Suetsugu and Nakagawa ${ }^{7}$ introduced the cell length and radius dependent total charge intensity $\mathrm{Q}$ and anode sputtering efficiency J, such that

$$
\begin{aligned}
& \mathrm{Q}=2.24 \mathrm{x}(1 / \mathrm{L}+1 / \mathrm{d})^{2} \cdot \mathrm{R}^{2} \cdot \exp \left\{-1.8 \mathrm{x}[\mathrm{R}(1 / \mathrm{L}+1 / \mathrm{d})]^{0.5}\right\} \\
& \mathrm{J}=\{1+\cos (2 \theta)\} / 2
\end{aligned}
$$

where $d=$ the anode-cathode gap and $\theta=\tan ^{-1}[R /(L+\delta)]$. Reasonable agreement with experimental data was achieved ${ }^{7}$ when $S$ was multiplied by $\mathrm{Q}$ and $\mathrm{J}$.

An additional variable for DIPs in the $g-2$ chamber is the alignment angle $\theta$. No systematic study of the dependence of $S$ on $\theta$ in the Penning cells has been reported. Welch ${ }^{9}$ observed an increase in pumping speed when the alignment of a $10 \mathrm{~mm}$ radius element was changed from $0^{\circ}$ to $22.5^{\circ}$. Suetsuga ${ }^{5}$ reported that the effect of misalignment was more profounded in smaller cells. Hartwig ${ }^{3}$ suggested that the effect of the misalignment on the pumping speed can be estimated by replacing $R$ by the effective radius $R(\theta)$, with $R(\theta)=$ $\mathrm{R} \cdot \cos \Theta-0.5 \mathrm{~L} \sin \Theta$.

In this paper, the pumping speeds of ion pump elements with different cell radii under high but misaligned magnetic fields are summarized and compared with the calculated values using some of these empirical formulae.

\section{PUMPING SPEED MEASUREMENT}

The pumping speeds of three commercial diode ion pump elements and two custom made elements have been measured in this study. The dimensions of these elements are listed in Table 1. All the elements have titanium cathode plates. The anodes are made of stainless steel. The anodes of the $5 \mathrm{~mm}$ element consist of 5 parallel plates with punched holes as Penning cells. The 
other four anodes are of cylindrical tubes. Both cathodes and anodes were cleaned in hydrofluoric-nitric acid, then baked in vacuum at $500^{\circ} \mathrm{C}$ for 40 hours before assembly.

A window frame electromagnet with a pole gap of $13 \mathrm{~cm}$ high, $25 \mathrm{~cm}$ wide and $120 \mathrm{~cm}$ long was used to provide the required magnetic field up to $15 \mathrm{KG}$. The homogeneity of the field between the gap was measured ${ }^{10}$ to be better than one part in $10^{3}$. A commercial ion pump power supply with $+5 \mathrm{KV}$ output was used to power the element. The pumping speeds of the elements were measured using the standard orifice method..$^{8}$ A pumping speed measurement system as shown schematically in Fig. 1 was constructed for this study. It consists of a test dome and a rectangular pump chamber which houses the-element to be tested. The orifice in the test dome has a calculated conductance $\mathrm{C}$ of $0.9 \mathrm{\ell} / \mathrm{sec}$ for nitrogen. The ion pump element was mounted parallel to the outer surface of the rectangular chamber. 'Misalignment' of the element up to $13^{\circ}$ was produced by tilting the chambers in reference to the magnet pole face. After roughing by a turbomolecular pump, a $20 \mathrm{\ell} / \mathrm{sec}$ ion pump was used as the holding pump when the magnet was not energized. Bayard-Alpert ionization gauges were used to monitor the pressures. Heavy steel envelopes were used to reduce the fringe field at the gauge tubes to less than 10 Gauss (i.e. at $B=15 \mathrm{KG}$ ). Nevertheless, it was necessary at each alignment angle to measure and correct for the sensitivity changes of the gauge tubes with changing magnetic field.

Background pressure of $10^{-8}$ Torr was maintained in the pump chamber by the holding ion pump. The holding pump was switched off after the magnet and the test element were energized. Pressure of mid $10^{-9}$ Torr could be reached when optimum magnetic field was applied. Most of the pumping speed measurements were carried out at pressures of low $10^{-7}$ Torr. Nitrogen was used as the test gas. It was bled into the gas inlet chamber through the variable leak valve and then pumped by the element through the orifice. To stabilize the element, 
approximately 2 Torr $\ell$ of nitrogen would initially be pumped by the element, which usually took a few days. At each alignment angle, the element would pump at the selected pressure and magnetic field for 30 minutes or longer, i.e. until a steady pressure had been maintained, then the data was recorded. The magnet was then ramped to the next B and the measurement was repeated. The gas throughput was adjusted periodically to compensate for the changes in pumping speed and to maintain the pressure level in the pump chamber. The speed measurements were repeated at other alignment angles. For each element, measurements were carried out at $0^{\circ}, 3^{\circ}, 6^{\circ}, 9^{\circ}, 11^{\circ}$ and $13^{\circ}$.

The pumping speeds $S$ of each element were derived from $S=C \cdot\left(P_{1}-P_{2}\right) / P_{2}$ with $P_{1}$ and $\ldots$ $\mathrm{P}_{2}$ the pressures of the gas inlet chamber and the pump chamber, respectively. The background pressures of the chambers were usually $50-100$ times lower than those during measurement therefore are not corrected for in the calculation. To compare the pumping behavior of different elements, the pumping speeds are divided by the number of cells to obtain the pumping speeds per cell. The pumping speeds are not corrected for the conductance restriction of the gaps between the anode and the cathodes. Using the formulae outlined in ref. 3 , the effect of the conductance restriction is estimated to be less than $12 \%$ for the worst case, i.e. the $6 \mathrm{~mm}$ element at its highest pumping speed.

\section{RESULTS AND DISCUSSION}

The measured pumping speeds per cell of each element at different $\theta$ are plotted versus B in Figures 2-6. As predicted by Hartwig and Kouptsidis' empirical formulae, $S$ increased with increasing $\mathrm{B}$ and peaked around 1-2 KG. The magnetic fields at the maximum pumping speeds are in reasonable agreement with the calculated $B_{t r}$ using equation (1), which are labelled in the figures. At $B \geq B_{t r}$, for elements of $6 \mathrm{~mm}$ and $5.5 \mathrm{~mm}$, the pumping speeds remained constant 
with increasing B but gradually decreased with increasing misalignment. For elements of $9 \mathrm{~mm}$ and $12 \mathrm{~mm}$. the pumping speeds dropped off rapidly with increasing $\mathrm{B}$ then remained relatively constant. Unlike the 5.5 and $6 \mathrm{~mm}$ elements, the pumping speeds of the $5 \mathrm{~mm}$ element also decreased with increasing B and may be caused by the misalignment of the anode plates.

The measured pumping speeds at $7.2 \mathrm{KG}$ and $12 \mathrm{KG}$ are plotted versus the cell radii and compared with those of ref 5 and 6 in Fig. 7. All the data are normalized, according to eq. (2), to a cell height of $1.9 \mathrm{~cm}$ and anode voltage of $5 \mathrm{KV}$. The calculated pumping speeds using equation (2) and equations (2)-(4) are also plotted in Fig. 7. The data from this study are in the same range as those reported in ref. 5 and 6 . Contrary to the findings of ref. 6 -that pumping speed increased with increasing cell area, this study shows a decrease in pumping speed with increasing cell size. The present results are 2-3 times lower than the calculated values using equations (2)-(4), and 5-6 times lower when the total charge intensity from eq. (3) is not included. These empirical formulae yield a much higher pumping speed than what can be achieved in practice.

The dependence of pumping speeds on the alignment angles are summarized in Fig. 8 for $7.2 \mathrm{KG}$. The pumping speeds of all the cells remained fairly constant when the misalignment was smaller than $6^{\circ}$. It decreased rapidly with further increase in misalignment. This trend remains true for $\mathrm{B}$ higher than $5 \mathrm{KG}$. The effect of the misalignment is more severe than predicted when the effective radius $R(\theta)$ is used in equations (2)-(4), especially at large misalignment. This is also shown in Fig. 8 where the calculated pumping speeds for $9 \mathrm{~mm}$ element are plotted alongside of the measured pumping speeds.

The measured pumping speeds at different pressures are shown in Fig. 9 for the $5.5 \mathrm{~mm}$ element. The pumping speed increased slightly with increasing pressure when B was less than 
$\mathrm{B}_{\mathrm{tr}}$. At a higher magnetic field, the pumping speed decreased with increasing pressure. This is not consistent with $S \propto \mathrm{P}^{0.1}$ of equation (2), which predicts an increase in pumping speed with increasing pressure.

\section{IV: SUMMARY}

At a high magnetic field, the measured pumping speeds of the 5.5 and $6 \mathrm{~mm}$ elements are significantly higher than those of the 9 and $12 \mathrm{~mm}$ elements. This is not consistent with the prediction of Suetsuga and Nakagawa ${ }^{7}$ based on total charge intensity within the anodes nor with the findings of Reid and Trickett, ${ }^{6}$ which are proportional to anode area. The pumping speeds of the elements of large cells decreased rapidly with increasing B, which are not predicted by the existing empirical formulae. At high $\mathrm{B}$, the effect of misalignment on the pumping speeds of elements cannot be explained by the effective radius $R(\theta)$, especially at alignment angles larger than $6^{\circ}$.

The results of this study indicate that smaller anode cells should be used for elements operated at high magnetic field, which also allow more cells to be packed in the same area. Misalignment of a few degree results in small decrease in pumping speed. Elements with plate anodes may be more susceptible to misalignment.

\section{ACKNOWLEDGEMENTS}

The authors would like to thank G. Boyle, D. Remski and C. Trabocchi for their excellent technical support in assembling the test stand and carrying out most of the measurements. One of the authors, H.C. Hseuh would like to thank T.S. Chou for lending us one of the test elements; and K.M. Welch for helpful discussions. This work was performed under the auspices of the U.S. Department of Energy. 


\section{REFERENCES}

${ }^{1}$ V.W. Hughes, in Particle, Strings \& Cosmology, World Scientist, Singapore, p.868, 1992.

2M.D. Maleve and E.M. Trachtenberg, Vacuum, 23, 403 (1973).

${ }^{3}$ H. Hartwig and J.S.Kouptsidis, J. Vac. Sci. Technol,, 11, 1154 (1974).

${ }^{4}$ T.S. Chou, J. Vac. Sci. Technol., A5, 3446 (1987).

${ }^{5}$ Y.Suetsugu and M. Nakagawa, Vacuum, 42, 625 (1991).

${ }^{6}$ R.J. Reid and B.A. Trickett, Proc. 7th Int. Vac. Cong., Vienna, Vol. 1, 89 (1977).

${ }^{7}$ Y. Suetsugu and M. Nakagawa, Vacuum, 42, 761 (1991).

${ }^{8}$ M.H. Hablanian, J.Vac. Sci. Technol., A5, 2552 (1987).

${ }^{9}$ K.M. Welch, Stanford Linear Accel. Center Tech. Note SLAC-TN-72-10, July 1972 (unpublished).

10H.C. Hseuh, W.S. Jiang and M. Mapes, J. Vac. Sci. Technol., A12, 1722 (1994).

\section{DISCLAIMER}

This report was prepared as an account of work sponsored by an agency of the United States This report was prepared as anited States Government nor any agency thereof, nor any of their Government. Neither the United States Government nor any agency the legal liability or responsiemployees, makes any warranty, express or implied, of any information, apparatus, product, or bility for the accuracy, completeness, or usefulness of any information, apparatus, product, process disclosed, or represents that its use would not infringe privately owe name, trademark, ence herein to any specific commercial product, procstitute or imply its endorsement, recommanufacturer, or otherwise does not necessarily constituto or any agency thereof. The views mendation, or favoring by the United States Governmentarily state or reflect those of the and opinions of authors expressed herein the 


\section{FIGURE CAPTIONS}

Fig. 1. Experimental setup for measuring the pumping speeds of the ion pump elements at various magnetic fields and alignment angles.

Fig. 2. Pumping speeds of element with plate type anodes of $5 \mathrm{~mm}$ cell radius.

Fig. 3. Pumping speeds of element with $5.5 \mathrm{~mm}$ cell radius.

Fig. 4. Pumping speeds of element with $6 \mathrm{~mm}$ cell radius.

Fig. 5. Pumping speeds of element with $9 \mathrm{~mm}$ cell radius.

Fig. 6. Pumping speeds of element with $12 \mathrm{~mm}$ cell radius.

Fig. 7. Pumping speeds versus cell radii at high magnetic field. All the data are normalized to $5 \mathrm{kV}$ and a cell length of $19 \mathrm{~mm}$ according to equation (2).

Fig. 8. Pumping speeds versus alignment angles at $7.2 \mathrm{KG}$. The dashed line is the calculated pumping speed of the $9 \mathrm{~mm}$ element using effective radius $R(\theta)$ and equations (2)-(4).

Fig. 9. The pumping speed of element with $5.5 \mathrm{~mm}$ cell radius at various pressures. 
Table 1. The Geometry of the Ion Pump Elements Tested

\begin{tabular}{llllll}
\multicolumn{2}{c}{ Anode } & \multicolumn{2}{c}{ Overall } & & \\
Radius & $\underline{\text { Length }}$ & Width & $\underline{\text { Length }}$ & $\underline{\text { Gap }}$ & $\underline{\text { No. Cells }}$ \\
\hline 5 & 23 & 37 & 300 & 5 & 53 \\
5.5 & 19 & 50 & 400 & 5 & 90 \\
6 & 19 & 80 & 220 & 5 & 92 \\
9 & 15 & 80 & 150 & 5 & 32 \\
12 & 25 & 130 & 240 & 8 & 57
\end{tabular}

all dimensions in $\mathrm{mm}$. 


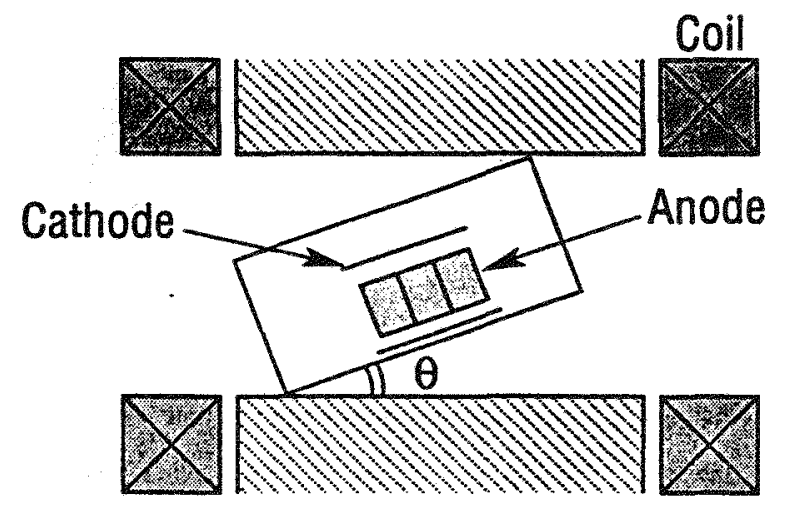

End View

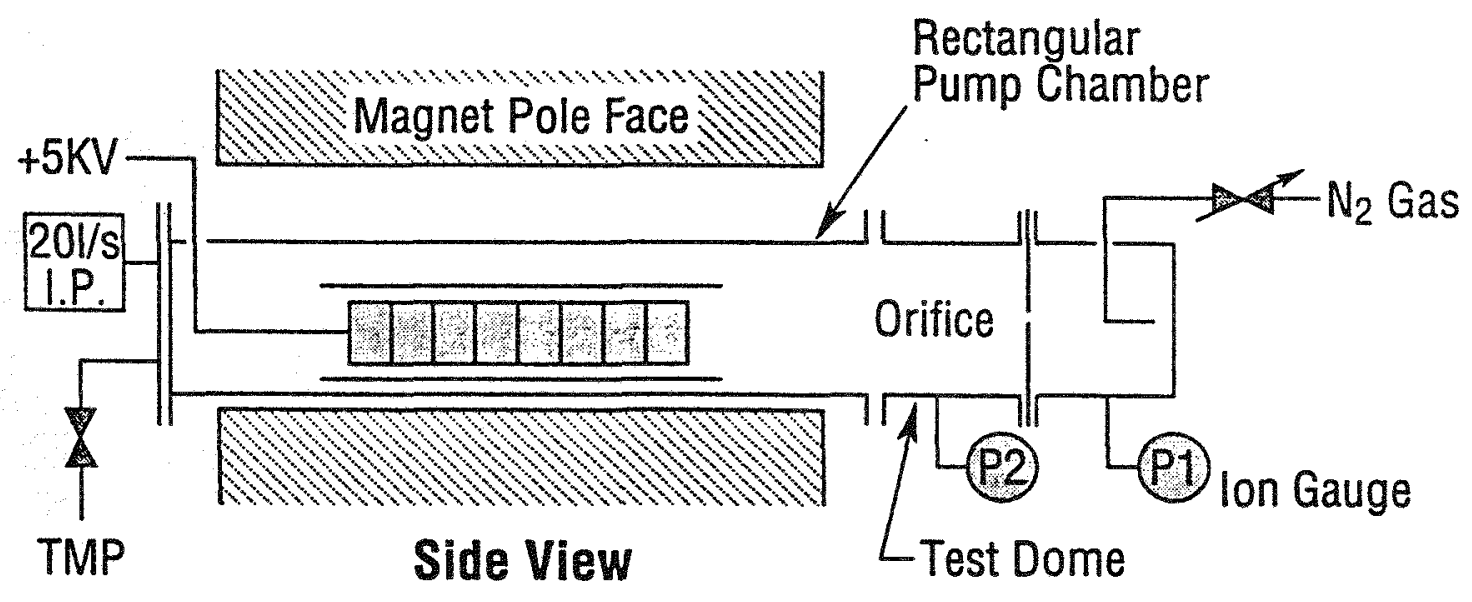

Figure 1 


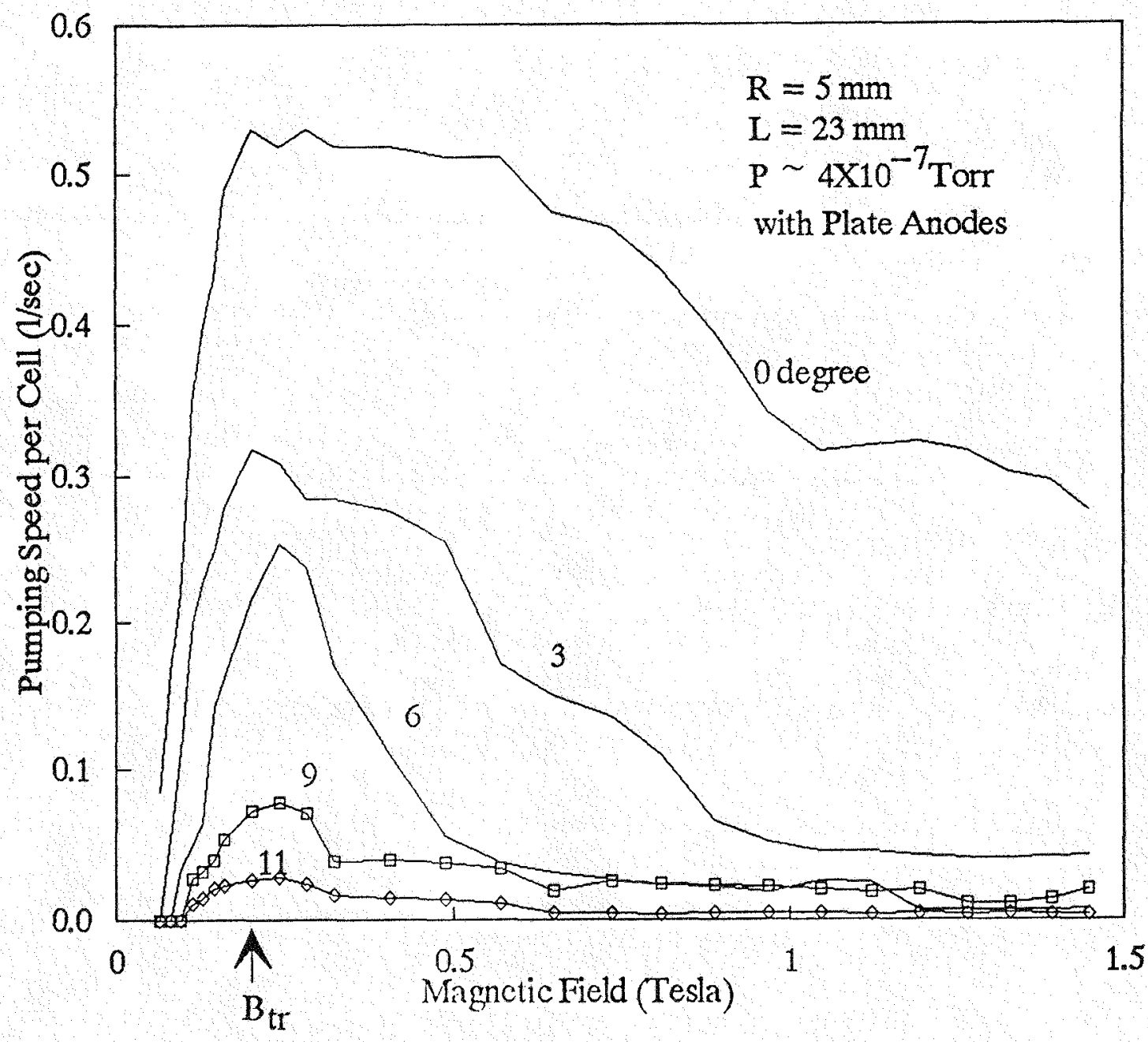

Figure 2 


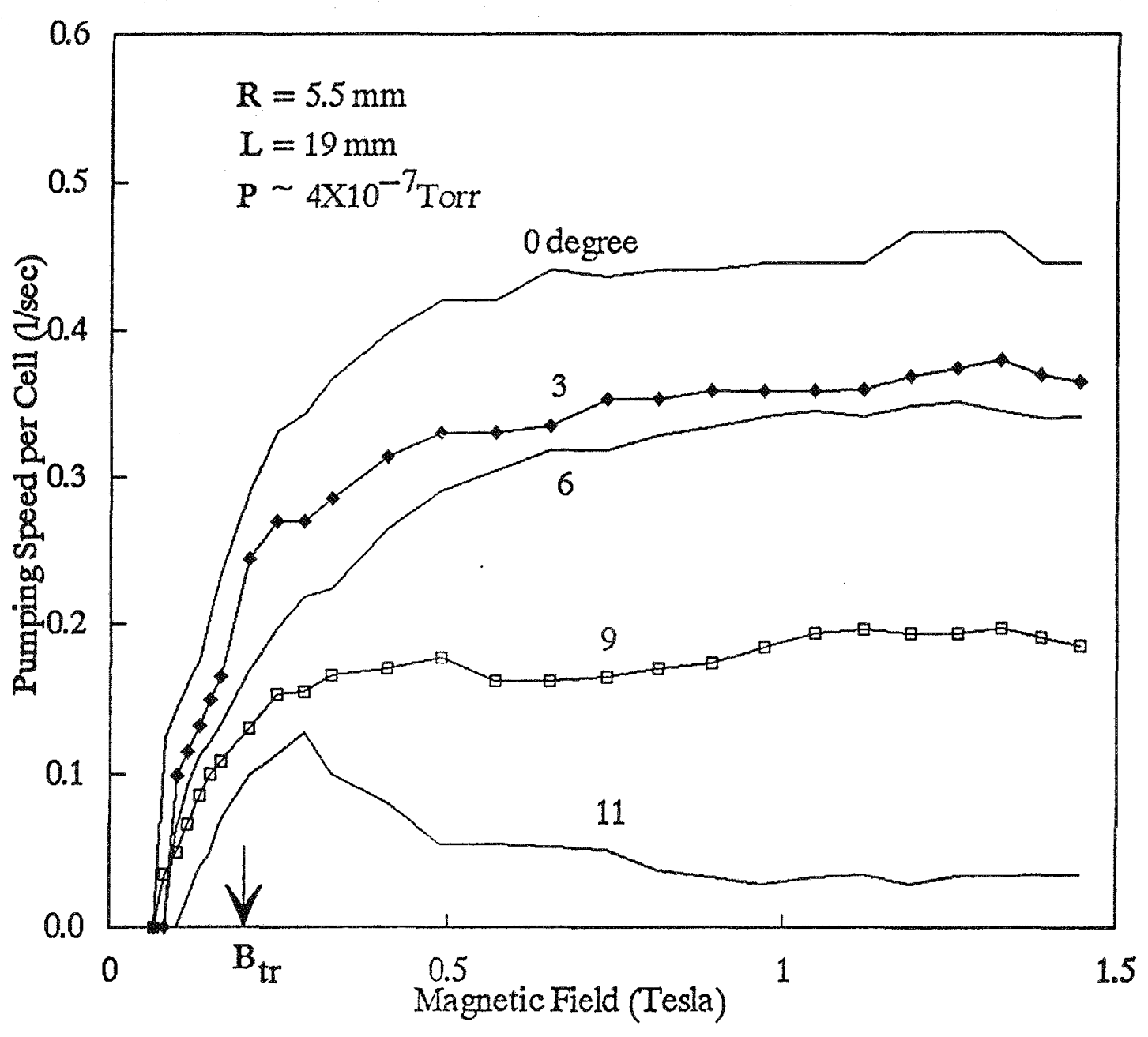

Figure 3 


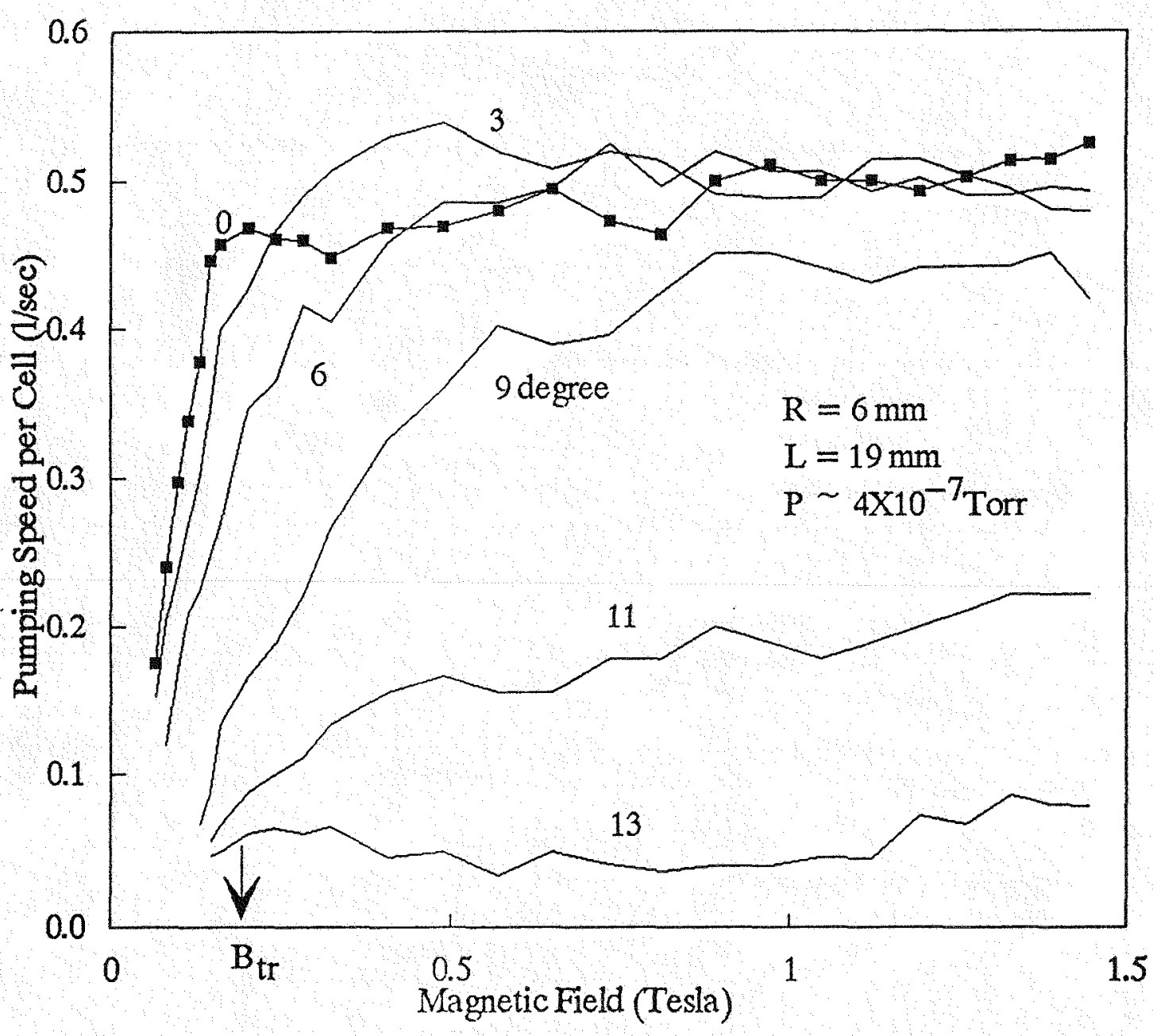

Figure 4 


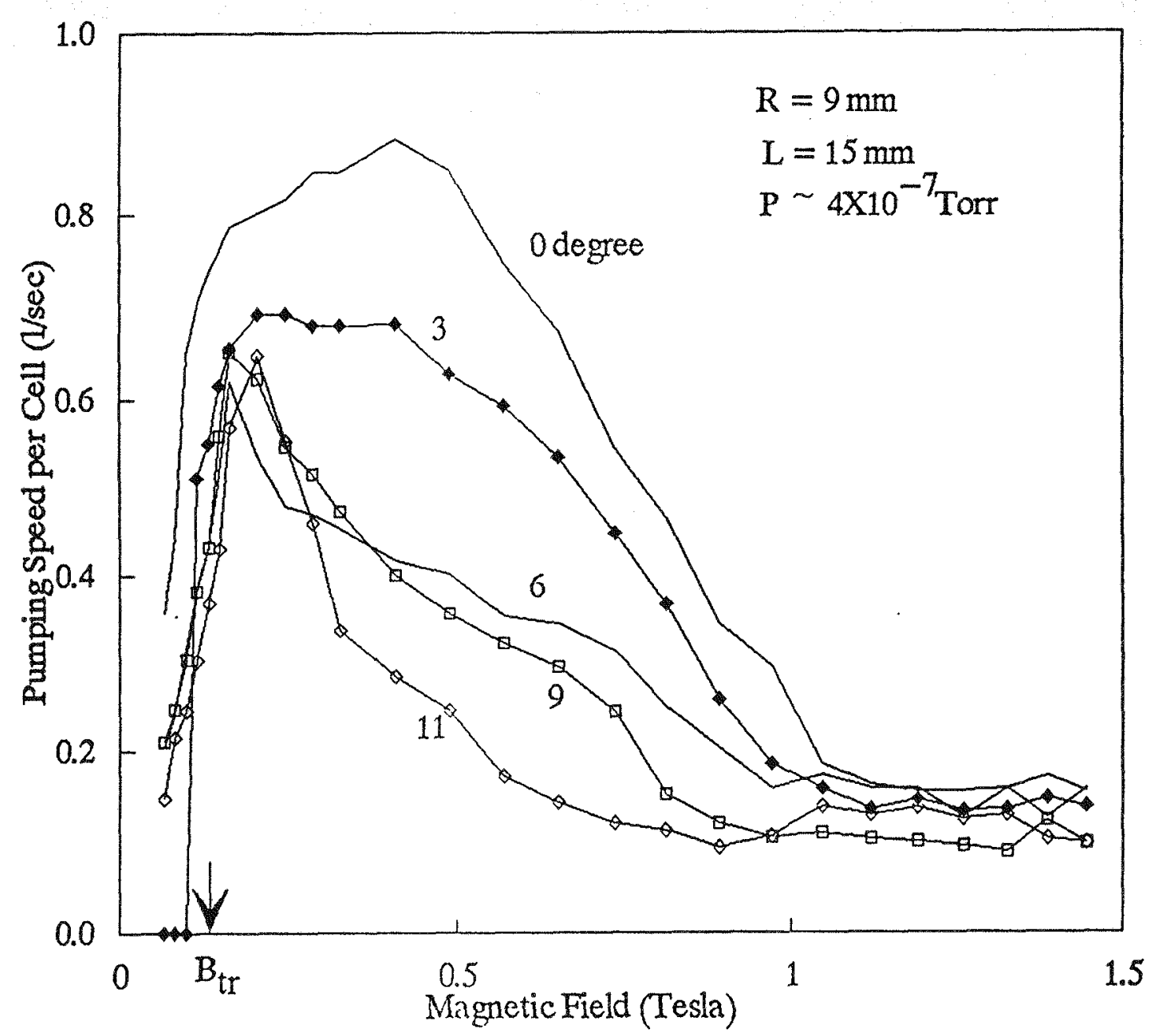

Figure 5 


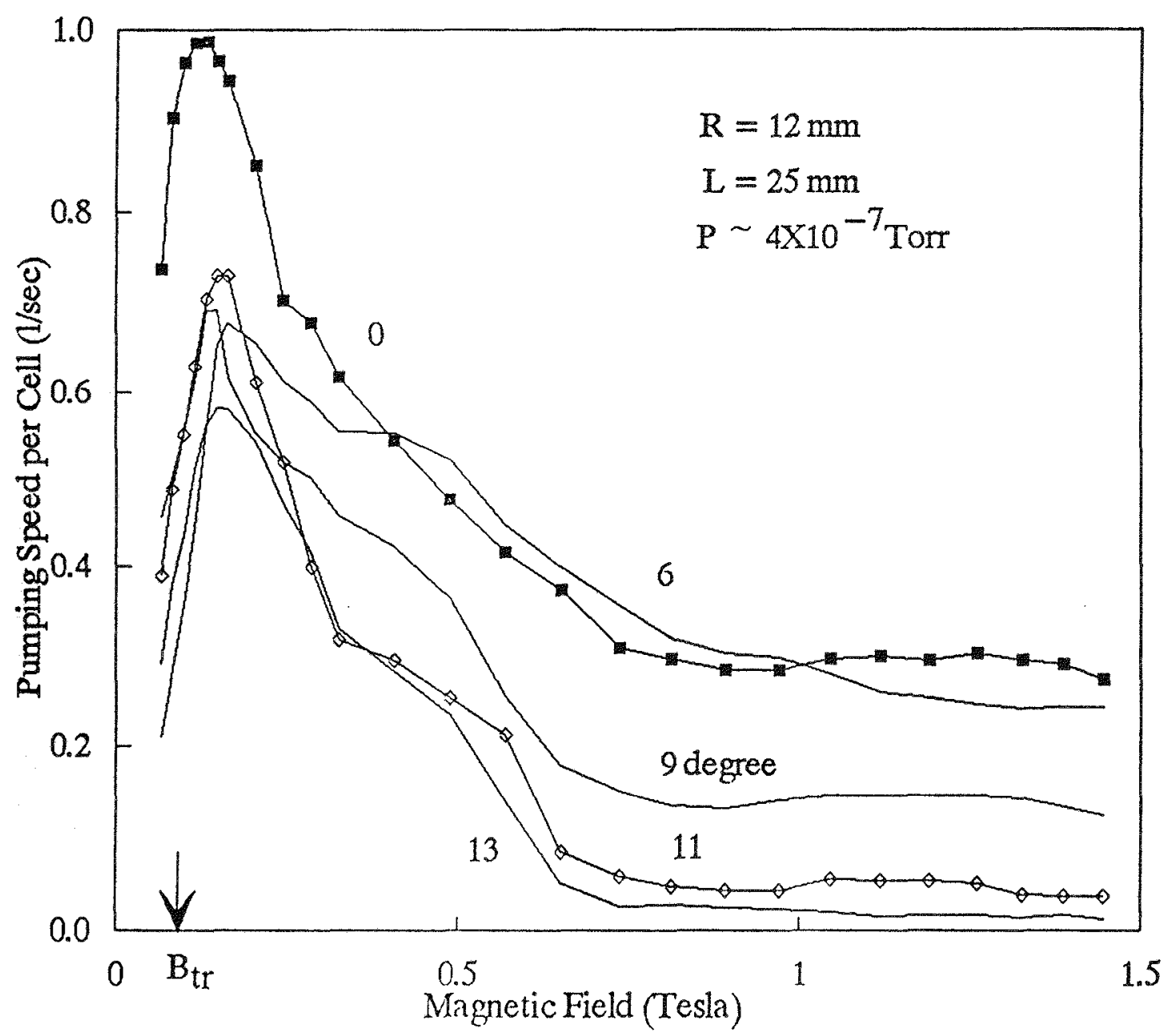

Figure 6 


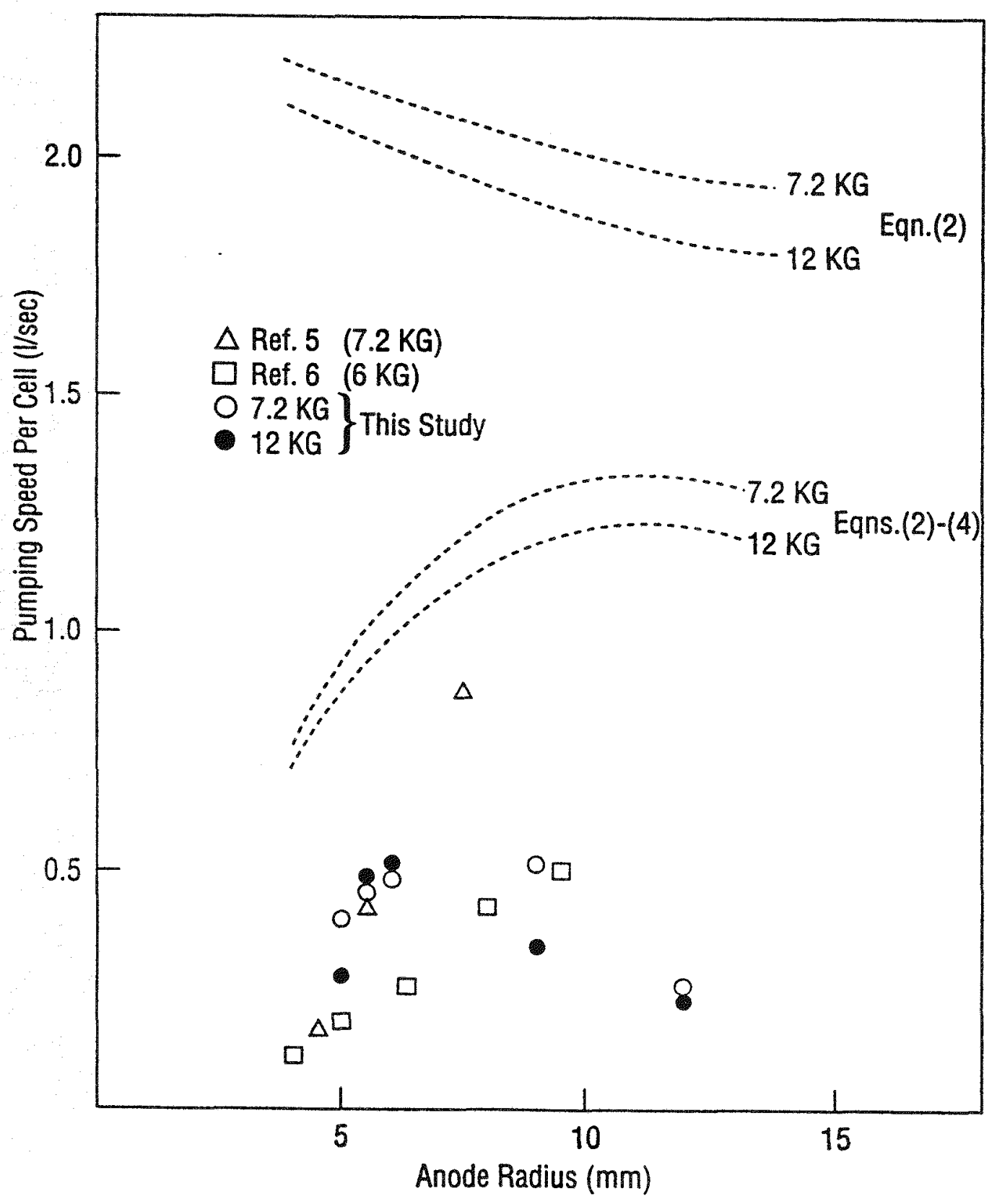

Figure 7 


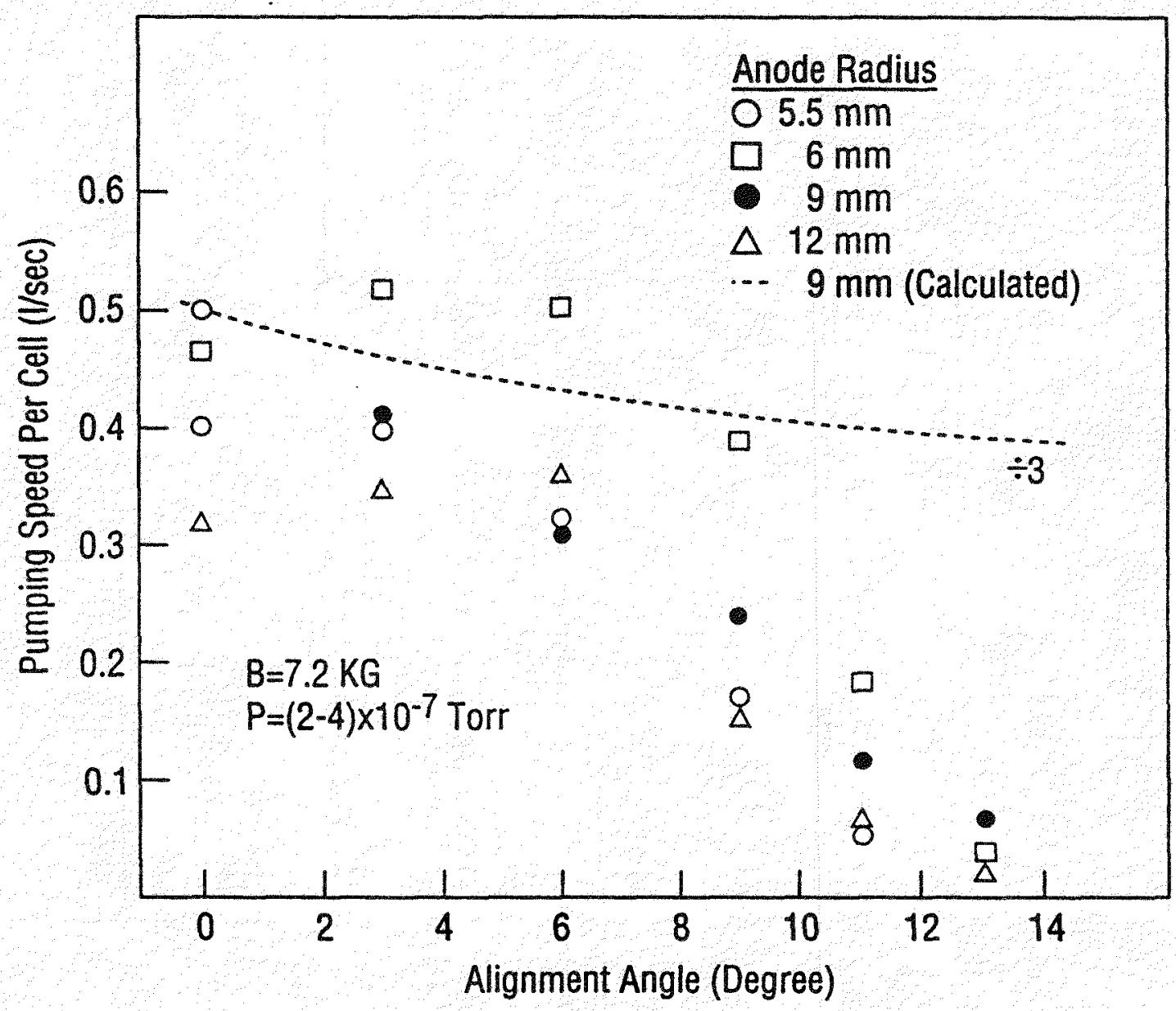

Figure 8 


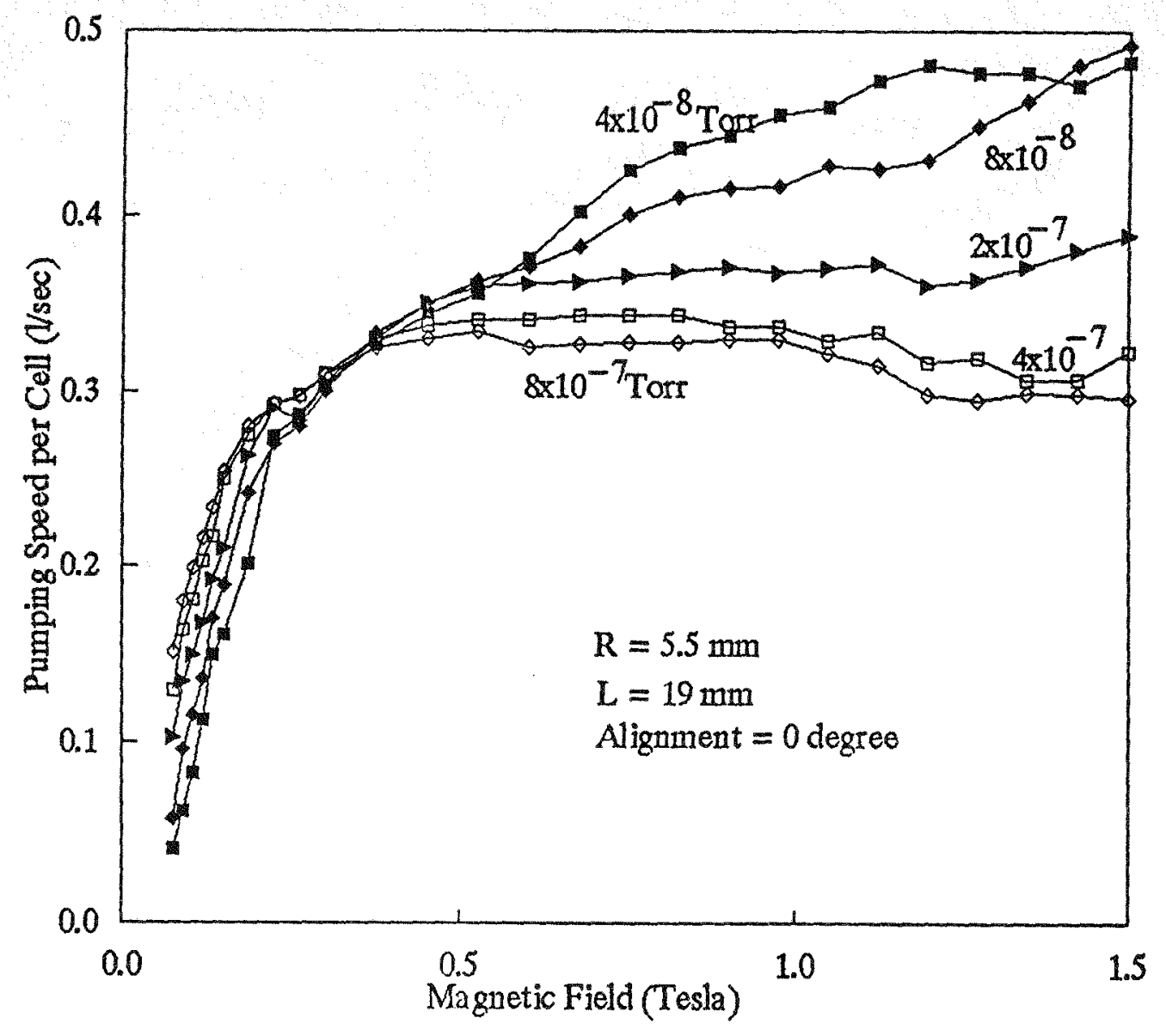

Figure 9 
